\title{
Control System Basic Design of Wall Climbing Robot for Hull Plate Spraying in Dock
}

\author{
Yuping $\mathrm{Li}^{1}$, Zhengyao $\mathrm{Yi}^{1,2^{*}}$, Yan $\mathrm{Lin}^{2}$, Zhuoshang $\mathrm{Ji}^{2}$ and Xiaoning Jiang ${ }^{2}$ \\ ${ }^{1}$ Dalian Cosco KHI Ship Engineering Co, Ltd. Dalian, China \\ ${ }^{2}$ School of Naval Architecture, Dalian University of Technology, Dalian, China \\ ${ }^{*}$ Corresponding author
}

\begin{abstract}
According to the design index of hull plate spraying in dock, a wall climbing robot for hull plate spraying in dock (WCR-HPSD) is designed, the functional requirements of the robot is discussed, the robot control requirements and control properties are analyzed, and the robot control models are established, including the driving walking control, the trajectory traversing control, the spraying reciprocating slide table control and the robot overall control. Finally, the human-computer interaction control scheme of robot is designed.
\end{abstract}

Keywords- ship shell plate painting; wall climbing robot; control system; basic design; control model

\section{INTRODUCTION}

The wall climbing robot for hull plate spraying in dock (WCR-HPSD) is important equipment for ship surface plate operation in the future, which has the hull plate adsorption, walking, equipped with spray gun spraying functions. Good performance of the WCR-HPSD [1-3], should also have paint mist protection and recycling function. A new type of WCRHPSD is designed in this paper, and the basic design of the control system is studied emphatically, such as the driving walking control, the trajectory traversing control, the spraying reciprocating slide table control and so on. At the end of the paper, the model of human-computer interaction integrated control platform and its control flow model are given.

\section{STRUCTURE AND BASIC FUNCTION OF ROBOT}

A. Robot Design Index

TABLE I. WCR-HPSD DESIGN INDEX

\begin{tabular}{|c|c|}
\hline Working index name and unit & Parameter \\
\hline Maximum height (m) & 40 \\
\hline Maximum span (m) & 300 \\
\hline Weight of robot body $(\mathrm{kg})$ & $<60$ \\
\hline Robot travel speed $(\mathrm{m} / \mathrm{s})$ & 0.12 \\
\hline $\begin{array}{l}\text { Horizontal moving distance of nozzle } \\
\text { reciprocating sliding table }(\mathrm{m})\end{array}$ & 1.1 \\
\hline Robot drive wheel distance (m) & $<0.8$ \\
\hline Body outline size $(\mathrm{L} \times \mathrm{W} \times \mathrm{H})(\mathrm{mm})$ & $1120 \times 800 \times 600$ \\
\hline $\begin{array}{l}\text { Horizontal moving speed of nozzle } \\
\text { reciprocating sliding table }(\mathrm{m} / \mathrm{s})\end{array}$ & 1 \\
\hline $\begin{array}{l}\text { Adjustable height of nozzle from outside } \\
\text { board of ship }(\mathrm{mm})\end{array}$ & $200 \sim 500$ \\
\hline
\end{tabular}

\section{B. Structure and Function of Robot}

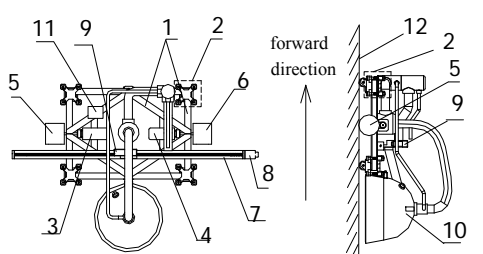

1. Robot Frame; 2. Permanent Magnet Adsorption Unit; 3. Left Driving Motor Driving Motor 4.; Right Driving Motor Driving Motor; 5. Left Wheel; 6. Right Wheel; 7. Spraying Reciprocating Slider; 8. Reciprocating Sliding Spray Drive Motor; 9. Lance Height Adjustment Motor; 10. Nozzle; 11. Detection Sensor Integrated Unit; 12. Ship Plate Surface

\section{FIGURE I. STRUCTURE DIAGRAM OF CLIMBING ROBOT}

The absorption function, which consists of four permanent magnetic adsorption units arranged around the frame, as shown No.2 in Figure 1. The permanent magnet with adjustable suction force is evenly distributed around the WCRHPSD body and is adsorbed on the surface of the hull plate to ensure that the robot can move forward, backward and turn along the hull plate flexibly.

The driving function, which consists of two driving motor mechanisms arranged on both sides of the robot frame, as shown No. 3,4,5,6 in Figure 1. When the two motors turn the same and have the same speed, the WCR-HPSD can move forward or backward in a straight line. When the two motor turns to the opposite direction and the same speed, the robot realizes the turning in place. When the two motor is turning forward or backward, the robot can not walk in accordance with the straight track as long as the speed is different, and it can realize curve walking.

The equipped with spraying gun operation function of WCR-HPSD is also important. The main function of the robot is equipped with spray gun to spray the ship surface. In order to meet the existing shipyard technology, the gun should be equipped with reciprocating spraying method, accompanied by robot walking straight, to achieve " $Z$ " shape spraying. Therefore, the robot body is equipped with spraying reciprocating slide table, as shown No. 7 in Figure 1. At the same time, a spraying reciprocating table drive motor is arranged, as shown No. 8 in Figure 1. In addition, the piping system, cable and testing element, which are equipped with other spraying materials, can be used as auxiliary for spraying. 
Adjust spray distance function, which has the nozzle of the spray gun, as shown No. 10 in Figure 1. A protective cover is provided around the spray gun to prevent paint mist from splashing, and the distance between the nozzle of the spray gun and the outer plate of the hull can be adjusted by a height adjusting motor, as shown No. 9 in Figure 1.

Other WCR-HPSD function features: mainly is the comprehensive testing, monitoring functions, including anti falling automatic detection function, paint mist concentration detection function, environmental temperature and humidity detection, track monitoring function, full coverage spray quality monitoring function [4-5].

\section{ROBOT CONTROL REQUIREMENTS AND ATTRIBUTES}

\section{A. Robot Control Requirements[6]}

1) The control system is convenient, high reliability, flexible operation, easy for operators to use; can use remote semi-automatic manual remote control, or automatic total station monitoring.

2) The multi pole moving speed of the WCR-HPSD can be set by the joystick of the remote controller, and the direction of motion and the speed of motion can be adjusted in real time so as to realize the omni-directional movement of the robot on the surface of the ship.

3) The surface of the hull plate is very large and very high. The working environment of the WCR-HPSD restricts its control mode. It adopts simple, practical and reliable wired remote control, and its wire control distance needs more than 50 meters.

4) The control system uses the electromagnetic valve to control the spray gun switch, at the same time, controls the robot movement, simulates the artificial spraying strictly, strictly walks according to the spraying track, and guarantees the spraying quality.

\section{B. Robot Control Attributes}

According to the control function principle of WCR-HPSD system, the overall control task property of robot can be expressed as formula (1)

$$
\eta=\{\alpha, \beta, \quad \theta, \rho, \varepsilon\}
$$

Among them, $\mathrm{T}$ represents the task set of the integrated control system, $\alpha$ represents the task set of robot driving control task as formula (2), $\beta$ represents the task set of robot trajectory tracking control for robot body as formula (3), $\theta$ represents the task set of robot spraying reciprocating slide table control as formula (4), $\rho$ represents the task set of robot feeding and recycling control as formula (5), $\varepsilon$ represents the task set of robot spray control and height adjustment as formula (6).

$$
\alpha=\left\{\alpha_{1}, \alpha_{2}, \alpha_{3}, \alpha_{4}\right\}
$$

$$
\begin{array}{r}
\beta=\left\{\beta_{1}, \beta_{2}, \beta_{3}, \beta_{4}, \beta_{5}\right\} \\
\theta=\left\{\theta_{1}, \theta_{2}, \theta_{3}, \theta_{4}, \theta_{5}\right\} \\
\rho=\left\{\rho_{1}, \rho_{2}, \rho_{3}, \rho_{4}\right\} \\
\varepsilon=\left\{\varepsilon_{1}, \varepsilon_{2}, \varepsilon_{3}, \varepsilon_{4}\right\}
\end{array}
$$

Among them, the $\alpha 1$ represents the No. 1 motor is forward, the $\alpha 2$ represents the No. 1 motor is reverse, the $\alpha 3$ represents the No. 2 motor is forward, and the $\alpha 4$ represents the No. 2 motor is reverse.

The $\beta 1$ represents the robot is straight up crawl, the $\beta 2$ represents the robot is turning to horizontal angle, the $\beta 3$ represents the robot is straight down crawl, the $\beta 4$ represents the entire surface painting is finish, and the $\beta 5$ represents the surface leakage painting part.

The $\theta 1$ represents the control motor of reciprocating slide table is positive direction, the $\theta 2$ represents the control motor of reciprocating slide table is opposite direction, the $\theta 3$ represents the spray gun moves on the reciprocating slide to the left, the $\theta 4$ represents the spray gun moves on the reciprocating slide to the right, and the $\theta 5$ represents the spray gun is reset in the middle of the slide table.

The $\rho 1$ represents the feeding system starts work, the $\rho 2$ represents the feeding system closed, the $\rho 3$ represents the vacuum recovery system starts work, and the $\rho 4$ represents the vacuum recovery system closed.

The $\varepsilon 1$ represents the spray gun starts work, the $\varepsilon 2$ represents the spray gun closed, the $\varepsilon 3$ represents the gun is approaching the hull plate adjustment, and the $\varepsilon 4$ represents the gun is far away from the hull plate adjustment.

The task analysis matrix of the control system can be expressed as equation (7).

$$
\eta=\left(\begin{array}{c}
\alpha \\
\beta \\
\theta \\
\rho \\
\varepsilon
\end{array}\right)=\left(\begin{array}{ccccc}
\alpha_{1} & \alpha_{2} & \alpha_{3} & \alpha_{4} & 0 \\
\beta_{1} & \beta_{2} & \beta_{3} & \beta_{4} & \beta_{5} \\
\theta_{1} & \theta_{2} & \theta_{3} & \theta_{4} & \theta_{5} \\
\rho_{1} & \rho_{2} & \rho_{3} & \rho_{4} & 0 \\
\varepsilon_{1} & \varepsilon_{2} & \varepsilon_{3} & \varepsilon_{4} & 0
\end{array}\right)
$$

\section{ROBOT CONTROL SYSTEM MODEL}

\section{A. Robot Driving Walking Control}

The wall climbing robot commonly used driving modes are pneumatic drive, hydraulic drive and motor drive types. Motor drive has no environmental pollution, fast response, high control accuracy, high power, low cost, easy control, high 
speed, continuous trajectory control with high precision, good servo performance and so on. According to the different actuators, the motor drive can be divided into three forms: AC servo motor drive, DC servo motor drive and stepping motor drive. Considering the hull surface operation range is larger, need high precision control in wall working environment, has high corrosion resistance in the spraying environment, need proof there is high, anti-burning, therefore, AC servo motor drive. Because the hull surface area is very large, the high precision motor is needed to control the spraying trajectory, and the environment at the seaside is very humid, which requires high corrosion resistance of the motor. In the dust spraying environment, the motor is required to have high explosion resistance and flame retardancy. Therefore, AC servo motor is selected for driving.

According to the actual situation of the hull plate spraying, artificial remote control is preferred, and the robot is controlled by two levels of upper and lower machine. Secondly, in order to work more efficiently, robot autonomous planning can be adopted, that is, in the absence of human operation, the lower computer can operate autonomously according to the instructions of the upper computer. The driving and walking control structure model is shown in Figure 2 .

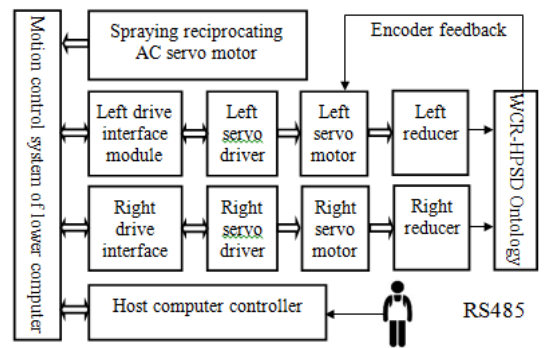

FIGURE II. THE DRIVING AND WALKING CONTROL STRUCTURE MODEL

\section{B. Robot Trajectory Traversing Control}

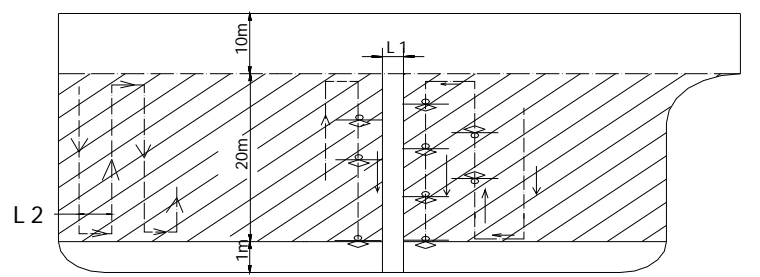

FIGURE III. FULL COVERAGE CONTROL TRAJECTORY MODEL

The whole ship surface traversal operation of spraying trajectory is the concentrated expression of intelligent control, and the strict trajectory planning and line tracking depend on automatic control. The trajectory of the robot should ensure the maximum spraying efficiency, avoid the overlap of the snake spraying trajectory, avoid the leakage between the tracks, and the robot rolling the spraying area.

Especially in the docking area of track, it can not only make the artificial coating area smaller, but also ensure that the robot can finish the spraying operation at the lowest point of the ship hull, so that the robot is safe and convenient to disembark.

Full coverage control trajectory model of hull plate surface is shown in Figure 3. Among them, the slash part represents the painted area, and the blank part indicates the uncoated area. Motion trajectory control structure model is shown in Figure 4.
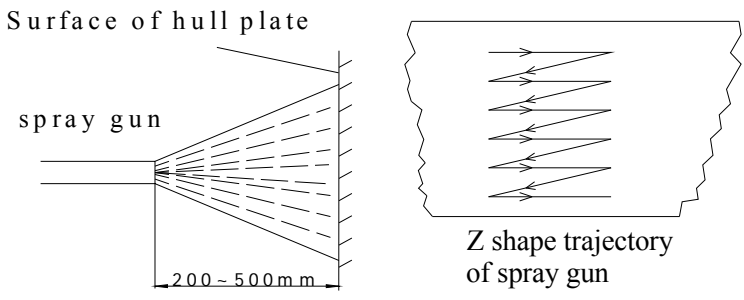

$\begin{array}{ll}\text { (a) Spraying distance of spray gun } & \text { (b) Zigzag spray path }\end{array}$ FIGURE V. ZIGZAG SPRAYING METHOD

\section{Robot Spraying Reciprocating Slide Table Control}

The height adjustment of the spray gun is achieved by adjusting the height of the motor and by adjusting the screw. The spraying reciprocating table adopts spiral transmission, which has the advantages of simple structure, convenient manufacture, accurate movement, stable operation, small noise and self-locking function [7]. The zigzag spraying method is shown in Figure.5.

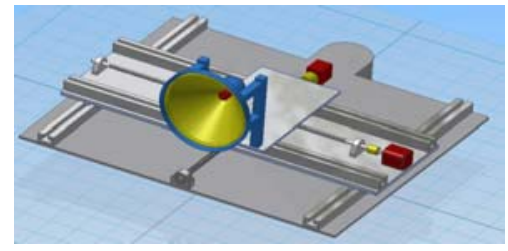

FIGURE VI. STRUCTURE DIAGRAM OF SPRAYING RECIPROCATING SLIDE TABLE

The $\mathrm{Z}$ shape spraying trajectory is realized by the straight line motion of the climbing robot, and the left and right movement of the reciprocating sliding table. The motion of each component is the independent movement of the motor control, as shown in Figure.6. The control structure model of spray reciprocating table is shown in Figure 7.

\section{HUMAN-COMPUTER INTERACTION CONTROL SCHEME}

Because the working environment of the ship factory is complex, the human computer interaction console control panel should be designed as a sealed form. The functions of the keys in the panel are defined as follows:

1) Start: press the power supply of each control component of the spraying robot after the press, and turn on the power supply indicator

2) Stop: press off the power supply of each control component of the spraying robot, then the spraying robot will stop immediately under the action of the electric brake 
3) Emergency braking: under normal circumstances, the "stop" button is used to disconnect the power supply of the spraying robot.

However, when the WCR-HPSD is working abnormally, the emergency braking can be used to quickly power off. At this time, the spraying robot will stop immediately under the action of the electric brake. Moreover, when the button is pressed, the start button is unable to start when the button is pressed, and the emergency brake must be bounced before it can be started again.
The function of each indicator in the human computer interaction console panel is defined as follows:

1) Power indicator: when the spraying robot turns on the power supply, it will turn off when the power is cut off.

2) Fault lamp: when the spraying robot is working abnormally, the fault lamp is bright, and after the fault is cleared, the fault lamp goes out.

In addition to the lights on the panel, there are also some software virtual indicating status lights on some of the operating interfaces.

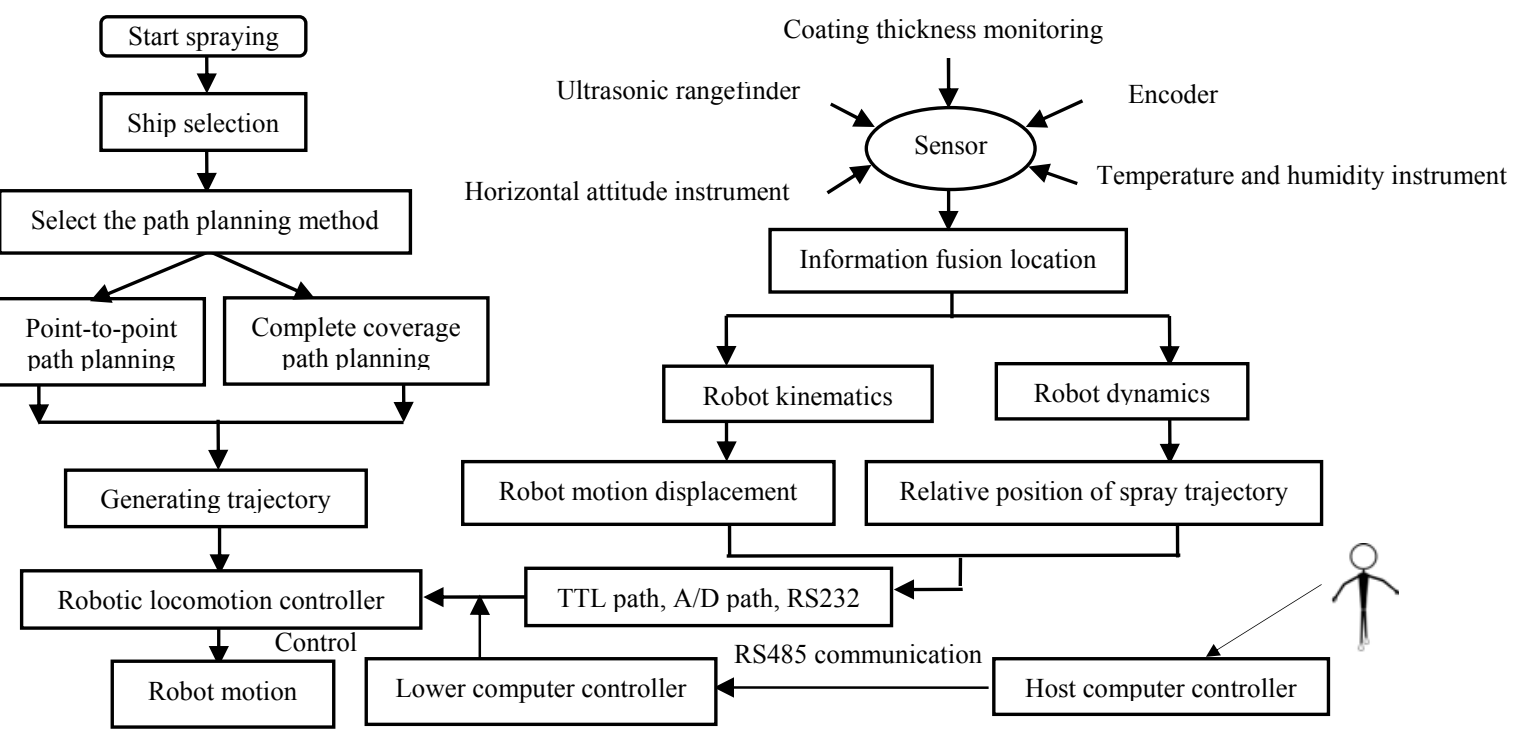

FIGURE IV. MOTION TRAJECTORY CONTROL STRUCTURE MODEL

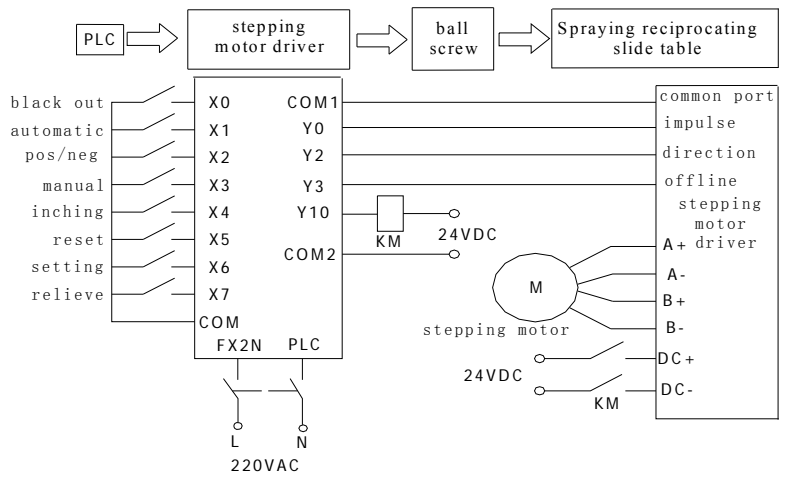

FIGURE VII. THE CONTROL STRUCTURE MODEL OF SPRAY RECIPROCATING TABLE

\section{CONCLUSION}

The basic functions of the WCR-HPSD control system include the reliable adsorption of the hull plate, the effective driving of the wall, the spraying gun operation, the adjustment of spraying distance, and the comprehensive detection and monitoring.

The basic elements of the WCR-HPSD control attributes include the ontology driven walking control, the ontology trajectory tracking control, spraying reciprocating slider control and so on.

The WCR-HPSD integrated control system consists of an ontology control unit, a feeding system control unit, a paint mist recovery control unit, a detection and monitoring unit, and a total station visual autonomous planning control. The system mainly includes operation processing, motion control, sensor interface, human-computer interaction, general IO control, data storage, communication interface and so on.

The man-machine interactive portable console and its control flow are the convenient control methods of WCRHPSD. With the total station visual function, it can realize the rapid independent planning operation.

\section{ACKNOWLEDGMENT}

This work was supported in part by High Tech Ship Research Plan of Ministry of Industry and Information Technology [2014]498.

\section{REFERENCES}

[1] Souto D, Fai A, Deibe A. A robot for the unsupervised grit-blasting of ship hulls[J]. International Journal of Advanced Robotic Systems. 2012, 9: 80-82. 
[2] Yi Z Y, Gong Y J, Wang Z W, et al. wall-attachment model and its simulation on a new wall-climbing robot for rust removal[J]. Journal of Sichuan University (Engineering Science Edition),2011,43(2):211216.

[3] Yi Z Y, Gong Y J, Wang Z W, et al. robot large wall climbing robots for boarding ship rust removal cleaner[J]. Robot, 2010, 32(4): 560567.

[4] Han S C, Kim J H, Kim J H. Design and experiment of automatic painting robot using permanent magnet mobile robot in ship cargo tank[J]. Journal of the Korea Academia Industrial. 2011, 12(12): 5450-5456.

[5] Markus E, Thomas V. Design and control of a lightweight magnetic climbing robot for vessel inspection[C]//IEEE 19th Mediterranean Conference on Control and Automation Corfu, GREECE: IEEE , 2011:1200-1205.

[6] Yi Z Y, Gong Y J, Wang Z W,et al. Dynamic modeling and analysis on a new type wall-climbing robot for ship wall rust removal[J].Journal of Mechanical Engineering, 2010, 46(15): 23-30.

[7] Akinfiev T, Armada M, Nabulsi S. Climbing cleaning robot for vertical surfaces [J].Industrial Robot, 2009, 36(4), 352-357. 